\title{
Adult Live Donor Hepatectomy: A Retrospective Pilot Study Comparing Four Strategies of Perioperative Pain Control
}

David M. Rosenfeld ${ }^{1 *}$, Terrence L. Trentman ${ }^{1}$, Daniel V. Simula ${ }^{1}$, Michael G. Ivancic ${ }^{1}$, Karl A. Poterack ${ }^{1}$, Kent P. Weinmeister ${ }^{1}$, David P. Seamans ${ }^{1}$, David C. Mulligan ${ }^{2}$ and Brie N. Noble ${ }^{3}$

${ }^{1}$ Department of Anesthesiology, Mayo Clinic, Arizona, USA

${ }^{2}$ Department of Transplant Surgery, Mayo Clinic, Arizona, USA

${ }^{3}$ Department of Biomedical Statistics and Informatics, Mayo Clinic, Arizona, USA

\begin{abstract}
Purpose: To compare the post operative pain control of four distinct management strategies in adult live donor hepatectomy.

Methods: Sixty-two ASA physical status I and II patients undergoing live donor hepatic resection from 2001 to 2008 were retrospectively organized into four groups for post-operative pain control. Group A received epidural catheter, Group B received PCA, Group C received intraoperative dexmedetomidine and PCA, and Group D received perioperative gabapentin, intraoperative dexmedetomidine, and PCA. Four day postoperative visual analog pain scores (VAS), intravenous morphine equivalent use, duration of hospitalization, and time until return of bowel function was measured.
\end{abstract}

Results: Mean visual analog pain score for a cumulative four day postoperative interval demonstrated 2.2 $( \pm 0.73)$ for epidural catheter, $3.4( \pm 1.13)$ for patient controlled analgesia (PCA), $3.0( \pm 1.42)$ for intraoperative dexmedetomidine infusion plus PCA, and $2.3( \pm 1.09)$ for perioperative gabapentin, intraoperative dexmedetomidine, combined with PCA. These results achieved statistical significance with $p=0.0443$. Total intravenous morphine equivalent use was similar between the three non-epidural groups. There was no difference in length of hospitalization or time until return of bowel function amongst the four groups.

Conclusions: Both epidural infusion and a three drug regimen of perioperative gabapentin, intraoperative dexmedetomidine, and PCA produced superior postoperative pain control compared with PCA alone or a combination of PCA and dexmedetomidine. The three drug regimen represents a preferred strategy as it provides optimal pain control without the theoretic risk of epidural hematoma in patients with a predictable postoperative coagulopathy. This pilot study serves as a template for future prospective examination of this three drug regimen versus epidural in major non-hepatic open abdominal surgery where post operative coagulopathy is less of a concern.

\section{Introduction}

The first successful transplantation of a liver segment from a live donor was reported in 1990 [1]. Initial experience with left hepatic lobe transplant from parent to child demonstrated the viability of the technique. Due to shortages of cadaveric livers for patients with endstage liver failure, adult to adult transplantation of the right hepatic lobe has gained acceptance. The right hepatic lobe is selected for adult recipients because of its larger size relative to the left lobe rendering it more adept to meet the physiologic needs of the adult recipient.

Live liver donor patients are generally young and healthy and undergo a high risk, exquisitely painful surgical procedure that includes bilateral sub costal incisions. A number of perioperative pain management techniques have been described including thoracic and lumbar epidural catheters [2-6], opiates via patient controlled analgesia or continuous infusion [6-8], intrathecal opiates [9], and paracetamol plus piritramide [8].

Several studies have documented abnormal coagulation parameters in donors after right lobe liver resection, including elevated prothrombin time and international normalized ratio (INR) and decreased platelet counts $[2,5,10,11]$. Due to concerns over epidural hematoma formation in the setting of postoperative coagulopathy a number of centers, including our own, have discontinued using epidural catheters for pain management in liver donor patients. This issue continues to be a source of discussion within the anesthesia and surgical community with no clear consensus $[11,12]$.

The objective of this study was to retrospectively review four primary postoperative pain management strategies for live liver donor patients: epidural, PCA alone, intraoperative dexmedetomidine plus PCA, and perioperative gabapentin with dexmedetomidine plus PCA. We suggest that a three drug regimen utilizing gabapentin, dexmedetomidine, and PCA will provide analgesia equivalent to that of an epidural without the inherent risk of epidural hematoma in the setting of post-operative coagulopathy.

\section{Methods}

After Institutional Review Board approval, a retrospective chart review was undertaken examining sixty-two patients undergoing donor hepatectomy utilizing four pain management strategies over a seven year interval from 2001-2008. Before liver donation each patient was carefully screened for acceptability via a multidisciplinary transplantation selection committee. All patients were American Society of Anesthesiology physical status I or II indicating excellent

${ }^{*}$ Corresponding author: David M. Rosenfeld, MD, Department of Anesthesiology, Mayo Clinic Arizona, 5777 E. Mayo Blvd, USA, Tel: 480-342-2452; E-mail: rosenfeld.david@mayo.edu

Received February 17, 2012; Accepted March 19, 2012; Published March 24 2012

Citation: Rosenfeld DM, Trentman TL, Simula DV, Ivancic MG, Poterack KA, et al. (2012) Adult Live Donor Hepatectomy: A Retrospective Pilot Study Comparing Four Strategies of Perioperative Pain Control. J Transplant Technol Res S1:007. doi:10.4172/2161-0991.S1-007

Copyright: ( 2012 Rosenfeld DM, et al. This is an open-access article distributed under the terms of the Creative Commons Attribution License, which permits unrestricted use, distribution, and reproduction in any medium, provided the original author and source are credited. 
overall health. Demographic information including mean age, gender, and blood type were collected.

All patients underwent surgery via bilateral subcostal incision by the same surgical team resecting the right hepatic lobe for transplantation. General endotracheal anesthesia was administered by one of seven anesthesiologists utilizing balanced technique with isoflurane or sevoflurane in air/oxygen mixture, non-depolarizing muscle relaxation, and intraoperative intravenous (IV) opioid titration. All patients were extubated in the operating room or shortly thereafter in recovery and were administered parenteral opioids to a visual analog pain score (VAS) goal of three or less.

Patients were retrospectively organized into 4 treatment groups dependent upon differences in perioperative pain management:

A. Epidural catheter infusion $(n=12)$.

B. Post operative intravenous opioid PCA $(n=9)$.

C. Intraoperative dexmedetomidine infusion and postoperative PCA $(n=18)$.

D. Intraoperative dexmedetomidine infusion, pre and postoperative gabapentin, and postoperative PCA $(n=23)$.

Epidurals were placed at vertebral levels T8-L1 early in the program but this technique was subsequently abandoned due to concern over epidural hematoma in the setting of observed postoperative coagulopathy. Epidurals were bolused and infused intraoperatively, and then the post-operative infusion was titrated between $0-12 \mathrm{ml} / \mathrm{hr}$ with bupivacaine $0.1 \%$ and fentanyl 10 micrograms $/ \mathrm{ml}$ until removal 2-3 days postoperative.

Intraoperative dexmedetomidine was initiated after induction of anesthesia and infusion was titrated to hemodynamic stability in a dose range 0.3-0.7 micrograms $/ \mathrm{kg} /$ hour. When dexmedetomidine was used intraoperative opioids were generally minimized after incision. Infusion was discontinued within one hour of arrival to recovery room.

Oral gabapentin was administered preoperatively in a dose of either 600 or $900 \mathrm{mg}$, and continued postoperatively three times per day up to seven days for a mean total perioperative dose of $4300 \mathrm{mg}( \pm 1800)$ in group D only. All patients were transitioned to oral oxycodone prior to discharge.
Primary endpoints were obtained via careful review of written anesthesia and recovery room records. The remaining data was gathered through review of available electronic medical documentation during the study period.

\section{Primary endpoints}

A. Visual analog pain scores (VAS; $0-10)$ at rest for each postoperative day (POD) 0-4, and cumulative POD 0-4 combined. These were obtained via routine nursing protocols.

B. Total post-operative IV morphine equivalent analgesic use from arrival to recovery room through POD 4.

PCAs contained predominantly morphine sulfate, with a few patients receiving hydromorphone or fentanyl. For the purpose of this study, postoperative opiate use was standardized to IV morphine equivalent using the following accepted conversion: fentanyl (0.1 $\mathrm{X}$ microgram dose), and hydromorphone (6.7 X mg dose) [13]. Intravenous ketorolac was administered in all four treatment groups in varied doses and therefore was not treated as a distinct modality. Ketorolac was converted to morphine IV equivalents and included in the post-operative analgesic use analysis utilizing the following published conversion across all four groups: ketorolac (0.4 X dose) [14].

C. Total length of hospitalization reported in days.

D. Time until return of bowel function determined by first documented bowel movement reported in days.

Statistical measures were compared using an overall F-test from a one-way ANOVA. Pairwise comparisons were evaluated using a Tukey's standardized range test, and contrast statements in a logistic regression model.

\section{Results}

A total of sixty-two patients were examined. Results are presented as mean (standard deviation). Age of the entire sample was 37.7 (11.8), with $54.8 \%$ male and $45.2 \%$ female. Blood type $\mathrm{O}$ was most common at $69.4 \%$ with the overwhelming majority of donors Caucasian (Table 1).

VAS for each of the first post-operative days $0-4$, and cumulatively for all four groups, is summarized in Table 2. Overall the cumulative

\begin{tabular}{|c|c|c|c|c|c|}
\hline & $\begin{array}{l}\text { Epidural } \\
(\mathrm{N}=12)\end{array}$ & $\begin{array}{l}\mathrm{PCA} \\
(\mathrm{N}=9)\end{array}$ & $\begin{array}{l}\mathrm{PCA}+\mathrm{Dex} \\
(\mathrm{N}=18)\end{array}$ & $\begin{array}{l}\mathrm{PCA}+\mathrm{Dex}+\text { Gabapentin } \\
(\mathrm{N}=23)\end{array}$ & $\begin{array}{l}\text { Total } \\
(\mathrm{N}=62)\end{array}$ \\
\hline \multicolumn{6}{|l|}{ Donor Age } \\
\hline $\mathrm{N}$ & 12 & 9 & 18 & 23 & 62 \\
\hline Mean (SD) & $36.8(11.75)$ & $39.9(10.19)$ & $29.4(9.49)$ & $43.9(10.63)$ & $37.7(11.82)$ \\
\hline Range & $(23.0-56.0)$ & $(25.0-54.0)$ & $(18.0-49.0)$ & $(20.0-55.0)$ & $(18.0-56.0)$ \\
\hline \multicolumn{6}{|l|}{ Donor Gender } \\
\hline Female & $4(33.3 \%)$ & $5(55.6 \%)$ & $8(44.4 \%)$ & $11(47.8 \%)$ & $28(45.2 \%)$ \\
\hline Male & $8(66.7 \%)$ & $4(44.4 \%)$ & $10(55.6 \%)$ & $12(52.2 \%)$ & $34(54.8 \%)$ \\
\hline \multicolumn{6}{|c|}{ Donor ABO Blood Group } \\
\hline A & $2(16.7 \%)$ & $2(22.2 \%)$ & $8(44.4 \%)$ & $5(21.7 \%)$ & $17(27.4 \%)$ \\
\hline B & $0(0 \%)$ & $1(11.1 \%)$ & $1(5.6 \%)$ & $0(0 \%)$ & $2(3.2 \%)$ \\
\hline $\mathrm{O}$ & $10(83.3 \%)$ & $6(66.7 \%)$ & $9(50 \%)$ & $18(78.3 \%)$ & $43(69.4 \%)$ \\
\hline \multicolumn{6}{|l|}{ Donor Race } \\
\hline Missing & $0(0 \%)$ & $0(0 \%)$ & $0(0 \%)$ & $4(17.3 \%)$ & 4 \\
\hline African American & $0(0 \%)$ & $1(11.1 \%)$ & $0(0 \%)$ & $0(0 \%)$ & $1(1.7 \%)$ \\
\hline Hispanic & $0(0 \%)$ & $0(0 \%)$ & $0(0 \%)$ & $2(8.7 \%)$ & $2(3.4 \%)$ \\
\hline Caucasian & $12(100 \%)$ & $8(88.9 \%)$ & $18(100 \%)$ & $17(73.9 \%)$ & 55 (94.8\%) \\
\hline
\end{tabular}

SD: Standard Deviation; PCA: Patient Controlled Analgesia; Dex: Dexmedetomidine

Table 1: Live Liver Donor Demographics. 
mean VAS for all 62 patients combined was 2.7 (1.2). Primary epidural analgesia resulted in the lowest VAS over the 4 day cumulative period at $2.2(0.73)$. This was closely followed by the three drug combination of gabapentin, dexmedetomidine, and PCA with VAS 2.3 (1.09). Superior pain control demonstrated in these groups achieved statistical significance when compared to the other two primary modalities with $\mathrm{p}=0.0443$ cumulatively over 4 days, and 0.0319 , and 0.0407 on POD 2, and POD 4 respectively. In both the epidural and the 3 drug group none of the mean VAS over the 4 day period averaged over 3.0, indicating excellent overall pain management.

Cumulative mean parenteral analgesic use in morphine equivalents for the first four post operative days is presented in Table 3. Since ketorolac was administered in all four groups in addition to opiates it was factored in per conversion [14] to arrive at the parenteral analgesic use, which is reported in morphine equivalents. The mean IV analgesic use is dramatically less in the epidural group explained by the use of $0.1 \%$ bupivacaine and fentanyl $10 \mathrm{mcg} / \mathrm{ml}$ infusion. We were unable to determine an accurate total of epidural opiate from review of the electronic medical record. When comparing the three non-epidural groups the use of IV analgesic was (Table 3) within a narrow range from 225.6 to $238.7 \mathrm{mg}$ morphine equivalent.

There was no statistically significant difference between the four groups in time to return of bowl function exhibited by first documented bowel movement with a range of 3.3 to 3.7 days, $p=0.8707$ (Table 4). There was also no statistically significant difference in length of hospitalization between the 4 groups with a range of 5.4 to 6.0 days, $\mathrm{p}$ $=0.8143$ (Table 4$)$. No patients required return to the operating room for surgical intervention.

\section{Discussion}

Despite efforts to educate the public and encourage organ donation, many patients die each year while waiting on a transplant list. Live donation has decreased but not eliminated this problem. Although a number of studies discuss anesthetic management of these cases, few focus on pain management and then only with small numbers of patients.

Some authors mention a multimodal approach to pain management including wound infiltration, epidural analgesia, intravenous opiates, and intrathecal opiates, but none describe use of anticonvulsant drugs such as gabapentin or centrally acting alpha-2 agonists like dexmedetomidine in this patient population. This study has allowed us to verify our clinical observation that a three drug combined strategy of gabapentin, dexmedetomidine, and PCA provides equivalent pain control to an epidural infusion without the theoretical risk of epidural hematoma.

Our institution has extensive clinical experience in the use of intraoperative dexmedetomidine. Continuous infusion of this drug originally indicated for intensive care sedation and analgesia, has been applied to the operative theater and been shown to improve intraoperative hemodynamic stability [15], and improve postoperative pain control with an opiate sparing effect $[16,17]$. In our practice we initially applied dexmedetomidine to neurologic, head and neck, and bariatric surgery with success. When we opted to eliminate epidurals for major liver resection and live liver transplant donors we anecdotally observed inferior pain control with PCA. As a result we utilized dexmedetomidine as an adjunct.

Administration of oral perioperative gabapentin has emerged as an adjuvant to improve pain control and to provide an opioid sparing effect [18-20]. Currently there is no consensus regarding the optimum dose and duration of perioperative treatment therefore many strategies are utilized [21]. At our institution we have utilized gabapentin with anecdotal effectiveness in various surgeries including orthopedic, gynecological, and major abdominal. In an attempt to reproduce the perceived pain control of epidurals in our live donor population

\begin{tabular}{|c|c|c|c|c|c|c|}
\hline & $\begin{array}{l}\text { Epidural } \\
(\mathrm{N}=12)\end{array}$ & $\begin{array}{l}\mathrm{PCA} \\
(\mathrm{N}=9)\end{array}$ & $\begin{array}{l}\mathrm{PCA}+\mathrm{Dex} \\
(\mathrm{N}=18)\end{array}$ & $\begin{array}{l}\mathrm{PCA}+\mathrm{Dex}+\text { Gabapentin } \\
(\mathrm{N}=23)\end{array}$ & $\begin{array}{l}\text { Total } \\
(\mathrm{N}=62)\end{array}$ & $p$ value \\
\hline $\begin{array}{l}\text { VAS score post-op day } 0 \\
\mathrm{~N} \\
\text { Mean (SD) } \\
\text { Range }\end{array}$ & $\begin{array}{l}12 \\
2.4(2.45) \\
(0.0-6.5)\end{array}$ & $\begin{array}{l}9 \\
4.2(0.74) \\
(3.0-5.3)\end{array}$ & $\begin{array}{l}18 \\
4.3(2.38) \\
(0.0-8.8)\end{array}$ & $\begin{array}{l}23 \\
3.0(2.22) \\
(0.0-8.0)\end{array}$ & $\begin{array}{l}62 \\
3.4(2.26) \\
(0.0-8.8)\end{array}$ & 0.0613 \\
\hline $\begin{array}{l}\text { VAS score post-op day } 1 \\
\qquad \mathrm{~N} \\
\text { Mean (SD) } \\
\text { Range }\end{array}$ & $\begin{array}{l}12 \\
2.3(1.74) \\
(0.0-5.2)\end{array}$ & $\begin{array}{l}9 \\
2.6(1.63) \\
(0.0-4.5)\end{array}$ & $\begin{array}{l}18 \\
2.5(1.76) \\
(0.0-6.0)\end{array}$ & $\begin{array}{l}23 \\
2.7(1.25) \\
(0.3-5.4)\end{array}$ & $\begin{array}{l}62 \\
2.5(1.53) \\
(0.0-6.0)\end{array}$ & 0.9346 \\
\hline $\begin{array}{l}\text { VAS score post-op day } 2 \\
\text { N } \\
\text { Mean (SD) } \\
\text { Range }\end{array}$ & $\begin{array}{l}12 \\
1.4(1.44) \\
(0.0-4.0)\end{array}$ & $\begin{array}{l}9 \\
3.1(1.25) \\
(1.0-5.0)\end{array}$ & $\begin{array}{l}18 \\
2.9(2.28) \\
(0.0-7.6)\end{array}$ & $\begin{array}{l}23 \\
1.9(1.41) \\
(0.0-5.0)\end{array}$ & $\begin{array}{l}62 \\
2.3(1.79) \\
(0.0-7.6)\end{array}$ & 0.0319 \\
\hline $\begin{array}{l}\text { VAS score post-op day } 3 \\
\text { N } \\
\text { Mean (SD) } \\
\text { Range }\end{array}$ & $\begin{array}{l}12 \\
2.1(1.40) \\
(0.0-4.7)\end{array}$ & $\begin{array}{l}9 \\
3.6(1.90) \\
(2.0-8.2)\end{array}$ & $\begin{array}{l}18 \\
2.9(1.66) \\
(0.0-5.4)\end{array}$ & $\begin{array}{l}23 \\
2.4(1.53) \\
(0.4-5.8)\end{array}$ & $\begin{array}{l}62 \\
2.7(1.63) \\
(0.0-8.2)\end{array}$ & 0.1464 \\
\hline $\begin{array}{l}\text { VAS score post-op day } 4 \\
\qquad \mathrm{~N} \\
\text { Mean (SD) } \\
\text { Range }\end{array}$ & $\begin{array}{l}12 \\
3.0(1.30) \\
(0.8-4.9)\end{array}$ & $\begin{array}{l}9 \\
3.2(2.25) \\
(0.7-7.8)\end{array}$ & $\begin{array}{l}18 \\
2.4(1.49) \\
(0.0-4.5)\end{array}$ & $\begin{array}{l}23 \\
1.7(1.25) \\
(0.0-3.8)\end{array}$ & $\begin{array}{l}62 \\
2.4(1.57) \\
(0.0-7.8)\end{array}$ & 0.0407 \\
\hline $\begin{array}{l}\text { Mean VAS score (day 0-day 4) } \\
\mathrm{N} \\
\text { Mean (SD) } \\
\text { Range }\end{array}$ & $\begin{array}{l}12 \\
2.2(0.73) \\
(0.9-3.4)\end{array}$ & $\begin{array}{l}9 \\
3.4(1.13) \\
(2.2-5.9)\end{array}$ & $\begin{array}{l}18 \\
3.0(1.42) \\
(0.1-5.4)\end{array}$ & $\begin{array}{l}23 \\
2.3(1.09) \\
(0.8-4.5)\end{array}$ & $\begin{array}{l}62 \\
2.7(1.20) \\
(0.1-5.9)\end{array}$ & 0.0443 \\
\hline
\end{tabular}

SD: Standard Deviation; PCA: Patient Controlled Analgesia; Dex: Dexmedetomidine 
Citation: Rosenfeld DM, Trentman TL, Simula DV, Ivancic MG, Poterack KA, et al. (2012) Adult Live Donor Hepatectomy: A Retrospective Pilot Study Comparing Four Strategies of Perioperative Pain Control. J Transplant Technol Res S1:007. doi:10.4172/2161-0991.S1-007

Page 4 of 5

\begin{tabular}{|c|c|c|c|c|c|c|}
\hline & $\begin{array}{l}\text { Epidural } \\
(\mathrm{N}=12)\end{array}$ & $\begin{array}{l}\mathrm{PCA} \\
(\mathrm{N}=9)\end{array}$ & $\begin{array}{l}\mathrm{PCA}+\mathrm{Dex} \\
(\mathrm{N}=18)\end{array}$ & $\begin{array}{l}\text { PCA+Dex+Gabapentin } \\
(\mathrm{N}=23)\end{array}$ & $\begin{array}{l}\text { Total } \\
(\mathrm{N}=62)\end{array}$ & $p$ value \\
\hline Morphine Equivalent Dose (mg) & & & & & & $<0.001^{\mathrm{a}}$ \\
\hline $\mathrm{N}$ & 12 & 9 & 18 & 23 & 62 & \\
\hline Mean (SD) & $48.1(45.20)$ & $238.7(239.74)$ & $225.6(85.79)$ & $235.1(74.79)$ & $196.7(131.84)$ & \\
\hline Range & $(1.0-127.8)$ & $(19.0-795.0)$ & $(45.0-347.0)$ & $(95.3-390.2)$ & $(1.0-795.0)$ & \\
\hline
\end{tabular}

SD: Standard Deviation; PCA: Patient Controlled Analgesia; Dex: Dexmedetomidine, mg: milligrams

a Upon evaluating the pairwise comparisons using Tukey's standardized range test, the mean analgesic total dose was significantly lower for the Epidural group when compared to the PCA, PCA+Dex, and PCA+Dex+Gabapentin groups $(p<0.05)$. Epidurals contained $0.1 \%$ bupivacaine and fentanyl 10 mcg/ml which was not included in opiate analysis

Table 3: Parenteral Analgesic Use (in morphine equivalent dose).

\begin{tabular}{|c|c|c|c|c|c|c|}
\hline & $\begin{array}{l}\text { Epidural } \\
(\mathrm{N}=12)\end{array}$ & $\begin{array}{l}\mathrm{PCA} \\
(\mathrm{N}=9)\end{array}$ & $\begin{array}{l}\text { PCA+Dex } \\
(\mathrm{N}=18)\end{array}$ & $\begin{array}{l}\text { PCA+Dex+Gabapentin } \\
(\mathrm{N}=23)\end{array}$ & $\begin{array}{l}\text { Total } \\
(\mathrm{N}=62)\end{array}$ & $p$ value \\
\hline $\begin{array}{l}\text { Length of Stay (days) } \\
\qquad \begin{array}{l}\mathrm{N} \\
\text { Mean (SD) } \\
\text { Range }\end{array}\end{array}$ & $\begin{array}{l}12 \\
6.0(2.95) \\
(4.0-15.0)\end{array}$ & $\begin{array}{l}9 \\
5.7(1.22) \\
(4.0-8.0)\end{array}$ & $\begin{array}{l}18 \\
5.4(1.29) \\
(4.0-8.0)\end{array}$ & $\begin{array}{l}23 \\
5.5(1.38) \\
(4.0-10.0)\end{array}$ & $\begin{array}{l}62 \\
5.6(1.72) \\
(4.0-15.0)\end{array}$ & 0.8143 \\
\hline $\begin{array}{l}\text { Return to bowel function (days) } \\
\mathrm{N} \\
\text { Mean (SD) } \\
\text { Range }\end{array}$ & $\begin{array}{l}12 \\
3.6(1.24) \\
(2.0-6.0)\end{array}$ & $\begin{array}{l}9 \\
3.3(0.71) \\
(2.0-4.0)\end{array}$ & $\begin{array}{l}18 \\
3.7(1.28) \\
(2.0-7.0)\end{array}$ & $\begin{array}{l}23 \\
3.4(1.37) \\
(2.0-7.0)\end{array}$ & $\begin{array}{l}62 \\
3.5(1.22) \\
(2.0-7.0)\end{array}$ & 0.8707 \\
\hline
\end{tabular}

SD: Standard Deviation; PCA: Patient Controlled Analgesia; Dex: Dexmedetomidine

Table 4: Duration of Hospitalization and Return of Bowel Function.

we eventually employed perioperative gabapentin to enhance the effectiveness of intraoperative dexmedetomidine plus PCA.

Generally our institutional goal is a VAS of 3 or below for a patient presenting with a baseline VAS of 0 in a post-surgical setting. In our first twelve epidural patients we observed an average four day VAS of 2.2 (0.73). When epidurals were abandoned and PCA alone $(n=9)$ was substituted the average four day VAS escalated to 3.4 (1.13). With the addition of intraoperative dexmedetomidine infusion to PCA the four day cumulative score improved to 3.0 (1.42), and further decreased to 2.3 (1.09) when the third drug gabapentin was introduced. This difference in VAS between the 4 groups achieved statistical significance over the cumulative four day postoperative interval, and on POD 2, and POD 4 (Table 2).

In addition to this result when examining the VAS for each day 0 through 4 only the epidurals and the three drug regimen consistently achieved scores at 3.0 or below. Overall the results from this retrospective pilot study support the hypothesis that when deviating from a well accepted and effective epidural technique, a pain management approach that utilizes multiple pharmacologic mechanisms delivers additional benefit with each class of drug introduced. Using epidural catheter as the benchmark we see the three drug method following very closely in effectiveness (VAS mean: 2.2 vs. 2.3), with less effect with a two and one drug approach in predictable order.

Table 3 presents the morphine equivalent analgesic usage between all four groups using standard accepted conversion factors [13,14]. Due to the retrospective nature of this pilot study we were unable to standardize to a single parenteral opioid agent. Most of the PCAs contained morphine with a few hydromorphone and fentanyl. Three patients required rotation to a second agent from the original PCA drug. The epidural infusions contained fentanyl $10 \mathrm{mcg} / \mathrm{ml}$ with $0.1 \%$ bupivacaine, so as expected less parenteral opioid was used in these patients with a mean of $48.1 \mathrm{mg}$ over four post-operative days. The use of ketorolac was seen across all groups and is included in the parenteral opiate analysis and is discussed in detail below. The three non-epidural groups required similar total morphine equivalent within a narrow range of 225.6-238.7 $\mathrm{mg}$ to achieve their four day cumulative pain scores.
We did not observe a significant difference in length of hospitalization between the four groups with a range of 5.4 days to 6.0 days (Table 4). The same can also be said for return of bowel function where no statistically significant difference was noted between the four groups with a very narrow range of 3.3 to 3.6 days until first documented bowel movement (Table 4).

There are clearly identifiable weaknesses to this pilot study which often relate to its retrospective design. The number of patients is not evenly distributed amongst groups with less in the epidural and PCA arms reflecting an evolution of practice. We understand that this may weaken our statistical analysis although the trend of observational results is consistent with our hypothesis.

Some live donor patients $(\mathrm{n}=18)$ in the program were excluded from analysis for various reasons. In most cases the written and electronic medical record (EMR) was incomplete with an inadequate number of measured pain scores, or failure to document accurate doses of opiates administered. There were also a small number of patients that received a single preoperative intrathecal injection of morphine in addition to PCA early in the program. This group was not sizable enough to power a full treatment group, therefore they were excluded.

All epidurals appeared to remain functionally in place for at least 48 hours postoperative and helped standardize this treatment arm. Thus the final study sample of sixty-two patients reflects only those whom we were confident the available information accurately reflected their clinical course, and were able to be cleanly assigned into a retrospective treatment group with sufficient power for a pilot study. The patients excluded were similar healthy and opiate naive patients as those included.

Our EMR would also not allow us to tabulate the total dose of opiate administered per patient from the epidurals which would have been effective to add to the analysis.

Ketorolac was administered in variable doses across all four groups and there were some patients in each group that did not receive the drug. This was compensated by an increase in IV opioids 
in these patients in the non-epidural groups. Since there is a published conversion for ketorolac to morphine [14] we were able to integrate this drug into our total IV analgesic calculations and feel this does not alter the conclusion of the analysis.

The EMR documentation during the study period did not allow us to accurately present data on issues such as post-operative nausea and emesis, or degree of sedation from opiates. It also would not allow us to determine pain scores beyond resting levels. No significant severe adverse events such as respiratory depression requiring naloxone were noted in the study patients.

Despite these weaknesses we are confident that our results are consistent with clinical observations of pain control in these patients when different primary modalities were employed, and provide an excellent foundation for future study. This would include a prospective design where we would narrow focus on epidural analgesia directly compared with gabapentin, dexmedetomidine, and PCA using patients undergoing major open abdominal non-liver resection surgery where coagulopathy and epidural hematoma are less of a concern.

Our final conclusions are as follows:

1. Continuous postoperative epidural catheter provides excellent pain control for these patients although the risk of axial hematoma prohibits its use in our practice.

2. The use of primarily PCA analgesia for these patients provides inferior pain control to that of epidural.

3. There is an incremental improvement in pain control with the addition of dexmedetomidine and then gabapentin in addition to PCA alone.

4. In our pilot study the use of a three drug regimen utilizing perioperative gabapentin, intraoperative dexmedetomidine infusion, and postoperative PCA provides analgesia equivalent to that of an epidural. Because there is no risk of epidural hematoma with this approach, it may be superior to an epidural infusion based technique.

5. A subsequent prospective study can be developed to directly compare epidural analgesia to the three drug regimen to further determine its effectiveness and safety profile.

\section{References}

1. Strong RW, Lynch SV, Ong TH, Matsunami H, Koido Y, et al. (1990) Successfu liver transplantation from a living donor to her son. N Engl J Med 322: 15051507.

2. Borromeo CJ, Stix MS, Lally A, Pomfret EA (2000) Epidural catheter and increased prothrombin time after right lobe hepatectomy for living donor transplantation. Anesth Analg 91: 1139-1141.

3. Chhibber A, Dziak J, Kolano J, Norton JR, Lustik S (2007) Anesthesia care for adult live donor hepatectomy: our experiences with 100 cases. Liver Transpl 13: $537-542$

4. Choudhry DK, Schwartz RE, Stayer SA, Shevchenko Y, Rehman M (1999) Anesthetic management of living liver donors. Can J Anaesth 46: 788-791.

5. Schumann R, Zabala L, Angelis M, Bonney I, Tighiouart H, et al. (2004) Altered hematologic profiles following donor right hepatectomy and implications for perioperative analgesic management. Liver Transpl 10: 363-368.

6. Yong BH, Tsui SL, Leung CC, Lo CM, Liu CL, et al. (2000) Management of postoperative analgesia in living liver donors. Transplant Proc 32: 2110.

This article was originally published in a special issue, Post-Transplantation Disorders handled by Editor(s). Dr. Piergiorgio Messa, IRCCS Fondazione Ca' Granda, Italy; Dr. Cheguevara I Afaneh, Weill Cornell Medical College, USA; Dr. Shaoyan Hu, The Children's Hospital of Soochow University, China
7. Beebe DS, Carr R, Komanduri V, Humar A, Gruessner R, et al. (2000) Living liver donor surgery: report of initial anesthesia experience. J Clin Anesth 12 157-161.

8. Cammu G, Troisi R, Cuomo O, de Hemptinne B, Di Florio E, et al. (2002) Anaesthetic management and outcome in right-lobe living liver-donor surgery. Eur J Anaesthesiol 19: 93-98.

9. Ko JS, Choi SJ, Gwak MS, Kim GS, Ahn HJ, et al. (2009) Intrathecal morphine combined with intravenous patient-controlled analgesia is an effective and safe method for immediate postoperative pain control in live liver donors. Liver Transpl 15: 381-389.

10. Shontz R, Karuparthy V, Temple R, Brennan TJ (2009) Prevalence and risk factors predisposing to coagulopathy in patients receiving epidural analgesia for hepatic surgery. Reg Anesth Pain Med 34: 308-311.

11. Siniscalchi A, Begliomini B, De Pietri L, Braglia V, Gazzi M, et al. (2004) Increased prothrombin time and platelet counts in living donor right hepatectomy: implications for epidural anesthesia. Liver Transpl 10: 1144-1149.

12. Choi SJ, Gwak MS, Ko JS, Kim GS, Ahn HJ, et al. (2007) The changes in coagulation profile and epidural catheter safety for living liver donors: a report on 6 years of our experience. Liver Transpl 13: 62-70.

13. Frasco PE, Sprung J, Trentman TL (2005) The impact of the joint commission for accreditation of healthcare organizations pain initiative on perioperative opiate consumption and recovery room length of stay. Anesth Analg 100: 162 168

14. Brown CR, Mazzulla JP, Mok MS, Nussdorf RT, Rubin PD, et al. (1990) Comparison of repeat doses of intramuscular ketorolac tromethamine and morphine sulfate for analgesia after major surgery. Pharmacotherapy 10 : 45S-50S.

15. Bekker A, Sturaitis M, Bloom M, Moric M, Golfinos J, et al. (2008) The effect of dexmedetomidine on perioperative hemodynamics in patients undergoing craniotomy. Anesth Analg 107: 1340-1347.

16. Gurbet A, Basagan-Mogol E, Turker G, Ugun F, Kaya FN, et al. (2006) Intraoperative infusion of dexmedetomidine reduces perioperative analgesic requirements. Can J Anaesth 53: 646-652.

17. Hofer RE, Sprung J, Sarr MG, Wedel DJ (2005) Anesthesia for a patient with morbid obesity using dexmedetomidine without narcotics. Can J Anaesth 52 176-180.

18. Dirks J, Fredensborg BB, Christensen D, Fomsgaard JS, Flyger $\mathrm{H}$, et al (2002) A randomized study of the effects of single-dose gabapentin versus placebo on postoperative pain and morphine consumption after mastectomy. Anesthesiology 97: 560-564.

19. Turan A, Karamanlioglu B, Memis D, Hamamcioglu MK, Tukenmez B, et al (2004) Analgesic effects of gabapentin after spinal surgery. Anesthesiology 100: 935-938.

20. Gilron I (2007) Gabapentin and pregabalin for chronic neuropathic and early postsurgical pain: current evidence and future directions. Curr Opin Anaesthesiol 20: 456-472.

21. Ho KY, Gan TJ, Habib AS (2006) Gabapentin and postoperative pain--a systematic review of randomized controlled trials. Pain 126: 91-101. 